\title{
EXTRAÇÃO E ANÁLISE FÍSICO-QUÍMICA DO ÓLEO DE SEMENTE DE UVA DAS VARIEDADES CABERNET SAUVIGNON E BORDÔ EXTRAÍDO POR SOXHLET
}

\author{
M. L. MENEZES ${ }^{1 *}$, J. F. MEDEIROS ${ }^{2}$, V. Y. KAJIHARA ${ }^{2}$, M. S. C. SAKAMOTO ${ }^{2}$, S. T. D. \\ BARROS $^{2}$, N. C. PEREIRA ${ }^{2}$ \\ ${ }^{1}$ Universidade Tecnológica Federal do Paraná, Curso de Engenharia Química \\ ${ }^{2}$ Universidade Estadual de Maringá, Departamento de Engenharia Química \\ *e-mail: maraisalm@hotmail.com
}

\begin{abstract}
RESUMO
O óleo de semente de uva tem características muito interessantes como propriedades antioxidantes, hidratantes, regeneradoras e de manutenção da pele e, também, a de aumentar o bom colesterol e diminuir o mau colesterol, triglicérides, e consequentemente os riscos de doenças cardiovasculares. Neste trabalho, foi utilizada uma técnica de extração convencional, o Soxhlet, para a extração do óleo de semente de uva das variedades Cabernet Sauvignon e Bordô secas às temperaturas de 30 a $80^{\circ} \mathrm{C}$, utilizando-se como solventes o diclorometano, o acetato de etila e o n-hexano. Após a extração, foram determinadas as melhores condições de extração. Em seguida, o óleo extraído com diclorometano, o qual apresentou maior teor de óleo extraído, e com n-hexano, solvente convencional na indústria, com sementes secas à 40 e $80^{\circ} \mathrm{C}$, foram caracterizados quanto ao perfil de ácidos graxos, viscosidade, massa específica, teor de umidade, índice de refração, índice de acidez, índice de iodo, índice de saponificação e matéria insaponificável. Com isso, pode-se verificar que os tratamentos não resultaram em óleos de composições muito distintas, com muitos parâmetros físico-químicos dentro do padrão de qualidade da ANVISA (1999), mesmo que o óleo analisado não tenha sido tratado.
\end{abstract}

\section{INTRODUÇÃO}

No Brasil, a vitivinicultura é uma prática consolidada, sendo que o país, em âmbito internacional, ocupou $16^{\circ}$ lugar em produção de uvas e $15^{\circ}$ lugar em produção de vinhos em 2006 (OLIVEIRA, 2010). Em 2014, segundo a União Brasileira de Vitivinicultura - UVIBRA -, o país produziu mais de 600000 toneladas de uva.

De acordo com Campos (2005), com relação ao total de uvas produzidas no Brasil, de 50 a $60 \%$ são direcionadas para a elaboração de vinhos, sucos e outros derivados, sendo gerada uma significativa quantidade de resíduos. Na elaboração de vinhos, a cada 100 litros, são gerados cerca de
$31,7 \mathrm{~kg}$ de resíduos na produção de vinho branco e cerca de $25 \mathrm{~kg}$ na de vinho tinto.

Esses resíduos vêm sendo utilizados como complemento na ração animal e adubo nos vinhedos (AHMADI e SIAHSAR, 2011). Grande parte desses resíduos é constituída das sementes das uvas, as quais possuem cerca de 10 a $20 \%$ de óleo, dependendo da variedade da uva (CAO e ITO, 2003).

$\mathrm{O}$ óleo de semente de uva é rico em tocoferol (vitamina $\mathrm{E}-$ antioxidante) principalmente sob a forma de alfa-tocoferol. Também possui grandes quantidades de ácidos graxos, destacando-se o elevado teor de ácido linoleico, que é um ácido graxo essencial ao ser humano (MORETTO e FETT, 1998), tornando, assim, a extração do 
óleo de semente de uva uma opção de destino mais nobre para este resíduo.

Como método de extração convencional de óleos a partir de grãos e sementes, tem-se o Soxhlet, no qual o óleo é extraído por meio de um solvente em refluxo contínuo. $\mathrm{O}$ uso de solvente tem a vantagem de produzir um farelo com menos de $1 \%$ de óleo, independente do teor inicial, tornando $\mathrm{o}$ método interessante, principalmente quando se utilizam grãos com baixo teor de óleo (OLIVEIRA, 2010).

Assim, sabendo-se que os estudos sobre a extração e a caracterização do óleo de semente de uvas brasileiras são escassos, é necessária uma maior pesquisa nesta área para que este produto seja oferecido ao mercado.

\section{MATERIAIS E MÉTODOS}

\subsection{Preparação da Matéria-Prima}

Antes do processo de extração, as sementes passaram por um processo de limpeza. Primeiramente, as sementes foram colocadas em peneiras e limpas em água corrente para a retirada de cascas, engaço e açúcar.

Em seguida, as sementes foram lavadas com água deionizada e com água deionizada aquecida a $100^{\circ} \mathrm{C}$. Elas foram então secas à temperatura ambiente, embaladas em sacos plásticos e guardadas sob refrigeração.

Para as extrações por Soxhlet, as sementes foram previamente secas em secador convectivo de leito fixo nas temperaturas de $30,40,50,60$ e 70 e $80^{\circ} \mathrm{C}$ e velocidade do ar de $0,8 \mathrm{~m} / \mathrm{s}$.

Antes de cada extração, as sementes serão trituradas em um triturador modelo TE345 por 10 segundos, homogeneizadas e trituradas por mais 10 segundos.

\subsection{Extração por Soxhlet}

Para as extrações com Soxhlet foram utilizados como solventes o n-hexano (PE: $68^{\circ} \mathrm{C}$ ), o acetato de etila (PE: $77,1^{\circ} \mathrm{C}$ ) e o diclorometano (PE: $40,7^{\circ} \mathrm{C}$ ), sendo as extrações realizadas na temperatura de ebulição do solvente.

As extrações do óleo foram realizadas em duplicata com aproximadamente $10 \mathrm{~g}$ de sementes previamente limpas, secas e moídas e $300 \mathrm{~mL}$ de solvente.

Os períodos de tempo estudados foram de 4, 8, 16 e 24 horas. Após o período de extração, a amostra contendo o óleo e o solvente ficou recolhida no balão. Em seguida, o óleo em solvente foi levado a um evaporador rotativo Fisatom 802 para a recuperação do solvente. $\mathrm{O}$ cálculo do teor de óleo extraído por Soxhlet foi realizado conforme a Equação 1.

$\%$ Teor de óleo $=\frac{\mathrm{m}_{\text {oleo }}}{\mathrm{m}_{\text {semente }}} 100$

Em que: $\mathrm{m}_{\text {óleo }}$ é a massa de óleo extraída, em gramas, e $\mathrm{m}_{\text {semente }}$ é a massa de sementes de uva, em gramas, utilizada em cada extração.

\subsection{Caracterização Físico-Química do Óleo}

A caracterização físico-química do óleo foi realizada para os óleos extraídos com diclorometano, o qual apresentou melhor condição de extração, e com n-hexano, solvente comumente utilizado industrialmente, nas temperaturas de extração de 40 e $80^{\circ} \mathrm{C}$.

Os parâmetros avaliados para a caracterização dos óleos extraídos foram: identificação e quantificação dos compostos orgânicos, por meio da cromatografia em fase gasosa. Além da cromatografia, foram realizadas as seguintes análises de acordo com a metodologia oficial do Instituto Adolfo Lutz (1985): índice de acidez, índice de saponificação, matéria insaponificável, índice de iodo e índice de refração, bem como massa específica, viscosidade e teor de umidade.

\section{RESULTADOS E DISCUSSÃO}


As Figuras 1 a 3 apresentam as superfícies de resposta para a avaliação dos teores de óleo extraídos por Soxhlet utilizando as sementes de uva da variedade Cabernet Sauvignon.

Figura 1 - Superfície de resposta para a extração utilizando o acetato de etila como solvente

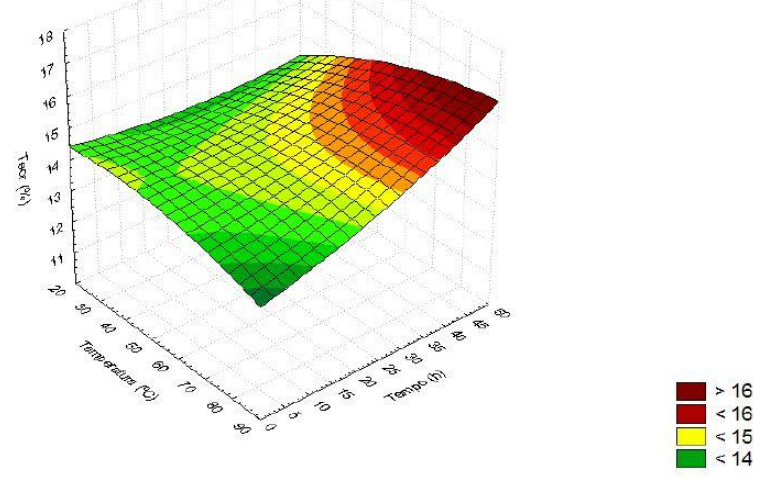

Figura 2 - Superfície de resposta para a extração utilizando o n-hexano como solvente

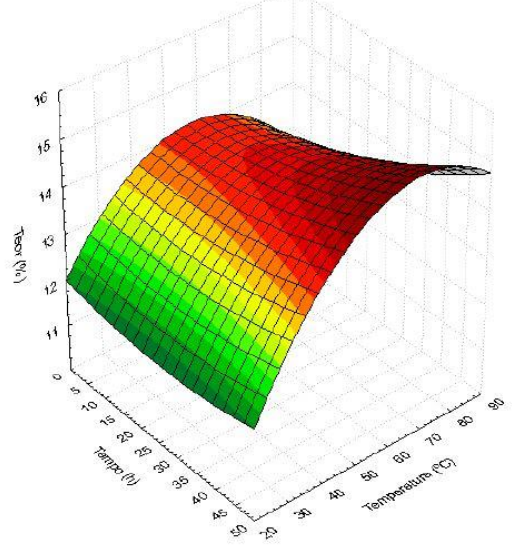

Figura 3 - Superfície de resposta para a extração utilizando o diclorometano como solvente
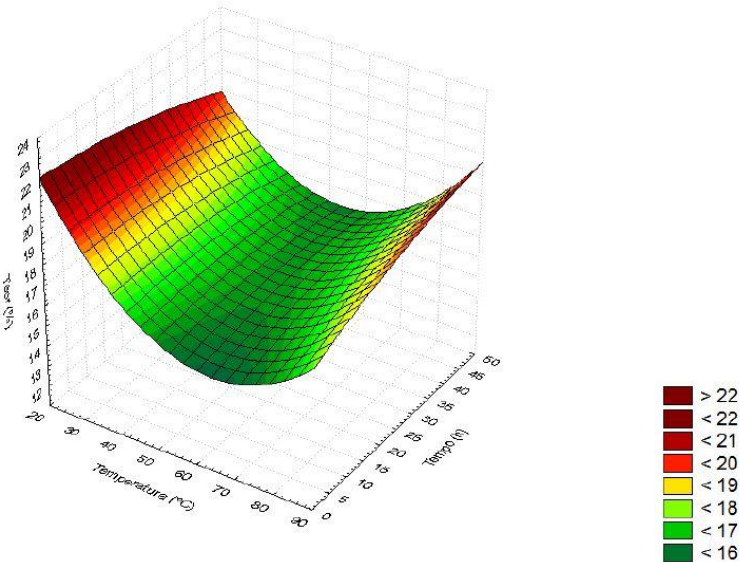

As Figuras 4 a 6 apresentam as superfícies de resposta para a avaliação dos teores de óleo extraídos por Soxhlet utilizando as sementes de uva da variedade Bordô.

Figura 4 - Superfície de resposta para a extração utilizando o acetato de etila como solvente

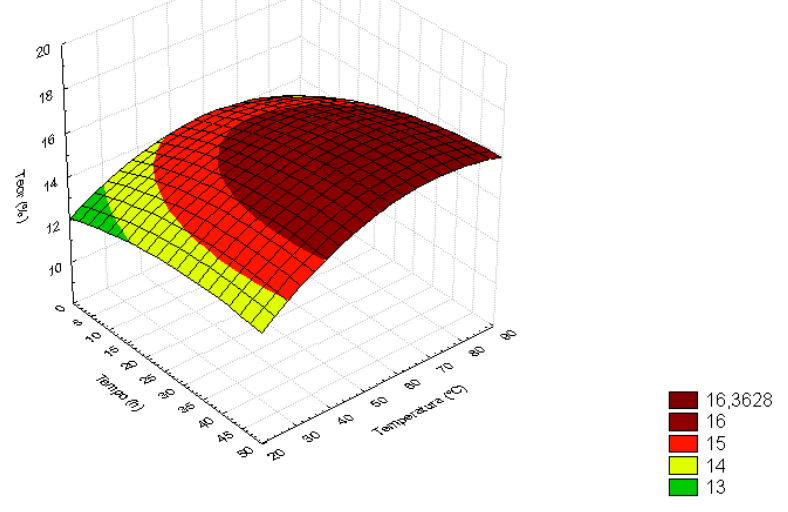

Figura 5 - Superfície de resposta para a extração utilizando o n-hexano como solvente 


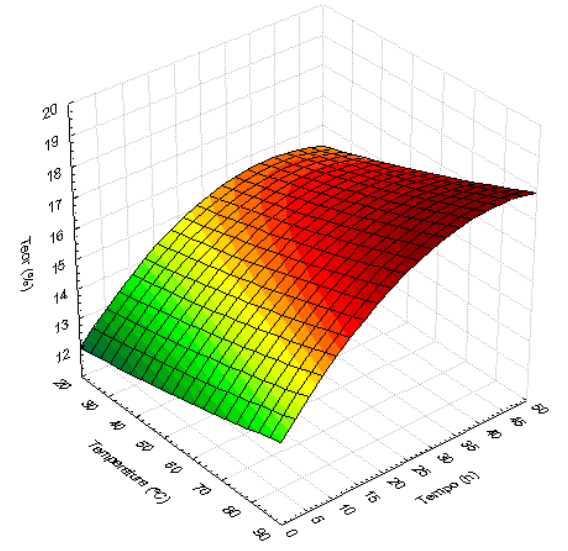

Figura 6 - Superfície de resposta para a extração utilizando o diclorometano como solvente

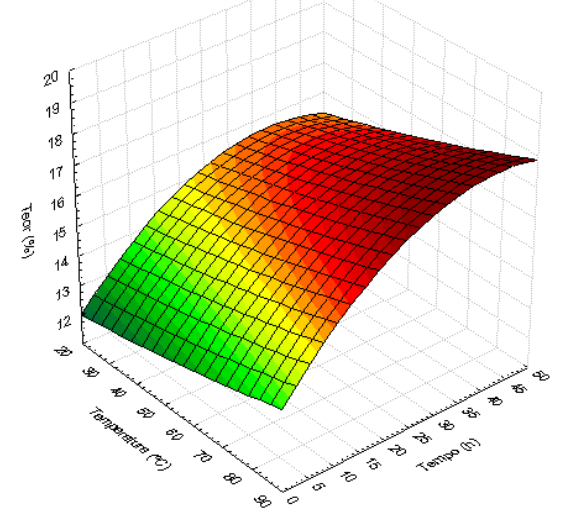

Por meio das Figuras 1 a 6, é possível verificar que a melhor condição de extração para ambas as variedades de sementes estudadas, com base no teor de óleo, foi obtida a altas temperaturas $\left(80^{\circ} \mathrm{C}\right)$ e utilizando o diclorometano como solvente.

Um fator importante quanto ao solvente é a capacidade de difusão que o diclorometano possui, devido a sua pequena estrutura. Esta característica faz com que haja uma maior facilidade na entrada do solvente nos poros das sementes, uma vez que é fácil entender que solventes menores terão um acesso mais fácil que os solventes de maior volume.

Além disso, dentre os solventes, o diclorometano é o que apresenta menor ponto de ebulição $\left(40,7^{\circ} \mathrm{C}\right)$. Deste modo, este é o solvente que realizou o processo de lixiviação mais vezes, acarretando, assim, em uma maior transferência de massa.

Nas Tabelas 1 e 2 estão apresentados os resultados da análise de variância para a extração por Soxhlet, utilizando como solvente o diclorometano e sementes de uva Cabernet Sauvignon e Bordô, respectivamente.

Tabela 1 - Análise de variância para a extração por Soxhlet utilizando sementes de uva Cabernet Sauvignon para a resposta teor de óleo $(\%)$

\begin{tabular}{cccccc}
\hline $\begin{array}{c}\text { Fonte de } \\
\text { variação }\end{array}$ & $\begin{array}{c}\text { Soma dos } \\
\text { quadrados }\end{array}$ & $\begin{array}{c}\text { Graus de } \\
\text { liberdade }\end{array}$ & $\begin{array}{c}\text { Soma dos } \\
\text { quadrados médios }\end{array}$ & $\mathrm{f}$ & $\mathrm{p}$-valor \\
\hline Temperatura $^{\text {Temperatura }}$ & 54,1306 & 1 & 54,1306 & 14,4805 & 0,0004 \\
Temperat $^{2}$ & 41,6763 & 1 & 41,6763 & 11,1488 & 0,0015 \\
Tempo & 0,7374 & 1 & 0,7374 & 0,1972 & 0,6587 \\
Tempo $^{2}$ & 1,0619 & 1 & 1,0619 & 0,2841 & 0,5962 \\
Temperatura* $^{\text {Tempo }}$ & 8,6521 & 1 & 8,6521 & 2,3145 & 0,1340 \\
Erro Total & 201,8614 & 54 & 3,7382 & & \\
Correção Total & 308,1197 & 59 & & & \\
\hline
\end{tabular}

Tabela 2 - Análise de variância para a extração por Soxhlet utilizando sementes de uva Bordô para a resposta teor de óleo (\%)

\begin{tabular}{cccccc}
\hline $\begin{array}{c}\text { Fonte de } \\
\text { variação }\end{array}$ & $\begin{array}{c}\text { Soma dos } \\
\text { quadrados }\end{array}$ & $\begin{array}{c}\text { Graus de } \\
\text { liberdade }\end{array}$ & $\begin{array}{c}\text { Soma dos } \\
\text { quadrados médios }\end{array}$ & $\mathrm{f}$ & $\mathrm{p}$-valor \\
\hline Temperatura & 0,0490 & 1 & 0,0490 & 0,0259 & 0,8727 \\
\hline
\end{tabular}




\begin{tabular}{cccccc}
\hline Temperatura $^{2}$ & 0,0410 & 1 & 0,0410 & 0,0231 & 0,8792 \\
Tempo & 16,6686 & 1 & 16,6686 & 8,8166 & 0,0044 \\
Tempo $^{2}$ & 13,8383 & 1 & 13,8383 & 7,3195 & 0,0091 \\
Temperatura* $^{\text {Tempo }}$ & 0,2676 & 1 & 0,2676 & 0,1415 & 0,7082 \\
Erro Total & 102,0917 & 54 & 1,8905 & & \\
Correção Total & 132,9562 & 59 & & & \\
\hline
\end{tabular}

Pela Tabela 1, para as sementes de uva da variedade Cabernet Sauvignon, verificouse que utilizando o diclorometano como solvente, somente a temperatura de secagem das sementes foi significativa, uma vez que o p-valor é menor que 5\%. Já pela Tabela 2, utilizando sementes de uva da variedade Bordô, o tempo foi significativo no processo.
As Tabelas 3 e 4 apresentam a quantificação dos principais ácidos graxos presentes no óleo de semente de uva das variedades Cabernet Sauvignon e Bordô, respectivamente. As médias seguidas de mesma letra minúscula nas linhas, não diferem estatisticamente entre si pelo teste de Tukey ao nível de 5\% de probabilidade.

Tabela 3 - Composição de ácidos graxos do óleo de sementes de uva, utilizando o diclorometano como solvente

\begin{tabular}{cccccc}
\hline $\begin{array}{c}\text { Ácido graxo } \\
(\mathrm{em} \mathrm{mg} / \mathrm{g} \text { de óleo) }\end{array}$ & \multirow{2}{*}{ Nomenclatura } & \multicolumn{2}{c}{ Cabernet Sauvignon } & \multicolumn{2}{c}{ Bordô } \\
& & $40^{\circ} \mathrm{C}$ & $80^{\circ} \mathrm{C}$ & $40^{\circ} \mathrm{C}$ & $80^{\circ} \mathrm{C}$ \\
\hline C 16:0 & Palmítico & $79,98^{\mathrm{b}} \pm 0,36$ & $80,24^{\mathrm{b}} \pm 0,80$ & $68,37^{\mathrm{a}} \pm 2,10$ & $65,16^{\mathrm{a}} \pm 0,45$ \\
C 18:0 & Esteárico & $37,88^{\mathrm{b}} \pm 0,23$ & $38,62^{\mathrm{b}} \pm 0,06$ & $32,22^{\mathrm{a}} \pm 0,21$ & $30,88^{\mathrm{a}} \pm 0,34$ \\
C 18:1n-9 & Oleico & $139,78^{\mathrm{a}} \pm 0,64$ & $138,30^{\mathrm{a}} \pm 0,41$ & $176,81^{\mathrm{c}} \pm 1,25$ & $164,46^{\mathrm{b}} \pm 0,39$ \\
C 18:2n-6 & Linoleico & $668,13^{\mathrm{c}} \pm 1,85$ & $665,67^{\mathrm{c}} \pm 3,06$ & $652,55^{\mathrm{b}} \pm 9,42$ & $636,51^{\mathrm{a}} \pm 2,46$ \\
\hline
\end{tabular}

Tabela 4 - Composição de ácidos graxos do óleo de semente uva, utilizando-se o n-hexano como solvente

\begin{tabular}{|c|c|c|c|c|c|}
\hline \multirow{2}{*}{$\begin{array}{c}\text { Ácido graxo } \\
\text { (em mg/g de óleo) }\end{array}$} & \multirow{2}{*}{ Nomenclatura } & \multicolumn{2}{|c|}{ Cabernet Sauvignon } & \multicolumn{2}{|c|}{ Bordô } \\
\hline & & $40^{\circ} \mathrm{C}$ & $80^{\circ} \mathrm{C}$ & $40^{\circ} \mathrm{C}$ & $80^{\circ} \mathrm{C}$ \\
\hline C 16:0 & Palmítico & $125,19^{b} \pm 0,42$ & $112,87^{\mathrm{a}} \pm 0,36$ & $126,34^{b} \pm 0,79$ & $115,5^{\mathrm{a}} \pm 0,30$ \\
\hline C $18: 0$ & Esteárico & $67,81^{\mathrm{a}} \pm 0,20$ & $75,50^{\mathrm{b}} \pm 0,21$ & $65,05^{\mathrm{a}} \pm 0,18$ & $89,32^{c} \pm 0,25$ \\
\hline C $18: 1 n-9$ & Oleico & $205,42^{\mathrm{b}} \pm 0,78$ & $199,32^{\mathrm{b}} \pm 0,69$ & $178,87^{\mathrm{a}} \pm 0,58$ & $173,97^{\mathrm{a}} \pm 0,66$ \\
\hline C $18: 2 n-6$ & Linoleico & $600,27^{\mathrm{b}} \pm 2,34$ & $609,03^{a} \pm 3,06$ & $595,55^{\mathrm{a}} \pm 2,94$ & $598,45^{\mathrm{a}} \pm 2,87$ \\
\hline \multirow{4}{*}{\multicolumn{3}{|c|}{$\begin{array}{l}\text { Os resultados obtidos mostram que o } \\
\text { óleo das sementes de ambas as variedades } \\
\text { apresentam composições similares, sendo que } \\
\text { o ácido graxo encontrado em maior }\end{array}$}} & C 16:0 & Palmítico & $55-110$ \\
\hline & & & C $18: 0$ & Esteárico & $30-60$ \\
\hline & & & C $18: 1$ & Oleico & $120-280$ \\
\hline & & & C $18: 2$ & Linoleico & $580-780$ \\
\hline
\end{tabular}
quantidade foi o linoleico. A Tabela 5 apresenta a composição em ácidos graxos do óleo refinado de semente de uva, segundo as normas da ANVISA (1999).

Tabela 5 - Quantificação dos ácidos graxos presentes no óleo de semente de uva refinado Ácido graxo Nomenclatura $\mathrm{mg} / \mathrm{g}$ de óleo

Fonte: ANVISA (1999).

Comparando os dados das Tabelas 3 e 5 , verifica-se que a composição de ácidos graxos do óleo das duas variedades de uva apresentam-se dentro das especificações da ANVISA (1999) utilizando-se o diclorometano como solvente. Em 
contrapartida, conforme Tabelas 4 e 5, para o óleo extraído com n-hexano, apenas os ácidos oleico e linoleico apresentam-se dentro da faixa esperada, sendo que os ácidos palmítico e esteárico encontram-se acima do valor especificado.

As Tabelas 6 e 7 apresentam os dados das análises de densidade relativa, teor de umidade (\%), índice de acidez em ácido oleico (\%), índice de iodo (Wijs), índice de refração $\left(\mathrm{n}_{\mathrm{D}}{ }^{40}\right)$, índice de saponificação $(\mathrm{mg}$ $\mathrm{KOH} / \mathrm{g}$ de óleo) e matéria insaponificável $(\%)$. As médias seguidas de mesma letra minúscula nas linhas, não diferem estatisticamente entre si pelo teste de Tukey ao nível de $5 \%$ de probabilidade.

Tabela 6 - Análises físico-químicas do óleo de semente de uva extraído com diclorometano

\begin{tabular}{|c|c|c|c|c|c|}
\hline & \multicolumn{2}{|c|}{ Cabernet Sauvignon } & \multicolumn{2}{|c|}{ Bordô } & \multirow{2}{*}{ ANVISA } \\
\hline & $40^{\circ} \mathrm{C}$ & $80^{\circ} \mathrm{C}$ & $40^{\circ} \mathrm{C}$ & $80^{\circ} \mathrm{C}$ & \\
\hline $\begin{array}{l}\text { Densidade } \\
\text { Relativa }\end{array}$ & $0,950^{\mathrm{b}} \pm 0,001$ & $0,934^{\mathrm{b}} \pm 0,001$ & $0,940^{\mathrm{b}} \pm 0,001$ & $0,943^{b} \pm 0,001$ & $0,923-0,926$ \\
\hline $\begin{array}{l}\text { Teor de } \\
\text { Umidade }\end{array}$ & $0,30^{\mathrm{d}} \pm 0,01$ & $0,26^{\mathrm{c}} \pm 0,01$ & $0,34^{\mathrm{d}} \pm 0,01$ & $0,22^{\mathrm{b}} \pm 0,01$ & - \\
\hline Índice de Acidez & $1,08^{\mathrm{a}} \pm 0,02$ & $1,08^{\mathrm{a}} \pm 0,06$ & $0,97^{\mathrm{a}} \pm 0,07$ & $0,83^{\mathrm{a}} \pm 0,02$ & Máximo 0,3 \\
\hline Índice de Iodo & $134,4^{\mathrm{b}} \pm 0,4$ & $135,1^{b} \pm 0,3$ & $132,7^{\mathrm{b}} \pm 0,6$ & $132,4^{\mathrm{b}} \pm 0,3$ & $130-138$ \\
\hline $\begin{array}{l}\text { Índice de } \\
\text { Refração }\end{array}$ & $1,463^{\mathrm{a}} \pm 0,001$ & $1,468^{\mathrm{a}} \pm 0,001$ & $1,467^{\mathrm{a}} \pm 0,001$ & $1,463^{\mathrm{a}} \pm 0,001$ & $1,473-1,477$ \\
\hline $\begin{array}{c}\text { Índice de } \\
\text { Saponificação }\end{array}$ & $190,8^{\mathrm{a}} \pm 0,7$ & $190,6^{\mathrm{a}} \pm 0,2$ & $188,3^{\mathrm{a}} \pm 0,6$ & $188,8^{\mathrm{a}} \pm 0,2$ & $188-194$ \\
\hline $\begin{array}{c}\text { Matéria } \\
\text { Insaponificável }\end{array}$ & $2,00^{\mathrm{b}} \pm 0,03$ & $1,50^{\mathrm{a}} \pm 0,03$ & $1,50^{\mathrm{a}} \pm 0,02$ & $1,50^{\mathrm{a}} \pm 0,02$ & Máximo 2,0 \\
\hline
\end{tabular}

Tabela 7 - Análises físico-químicas do óleo de semente de uva extraído com n-hexano

\begin{tabular}{cccccc}
\hline & \multicolumn{2}{c}{ Cabernet Sauvignon } & \multicolumn{2}{c}{ Bordô } & ANVISA \\
& $40^{\circ} \mathrm{C}$ & $80^{\circ} \mathrm{C}$ & $40^{\circ} \mathrm{C}$ & $80^{\circ} \mathrm{C}$ & \\
\hline $\begin{array}{c}\text { Densidade } \\
\text { Relativa }\end{array}$ & $0,909^{\mathrm{a}} \pm 0,001$ & $0,898^{\mathrm{a}} \pm 0,001$ & $0,914^{\mathrm{a}} \pm 0,001$ & $0,907^{\mathrm{a}} \pm 0,001$ & $0,923-0,926$ \\
Teor de & $0,16^{\mathrm{b}} \pm 0,01$ & $0,16^{\mathrm{b}} \pm 0,01$ & $0,10^{\mathrm{a}} \pm 0,01$ & $0,12^{\mathrm{a}} \pm 0,01$ & - \\
Umidade & & & & \\
Indice de Acidez & $1,05^{\mathrm{a}} \pm 0,04$ & $0,93^{\mathrm{a}} \pm 0,04$ & $2,50^{\mathrm{b}} \pm 0,04$ & $2,58^{\mathrm{b}} \pm 0,04$ & Máximo 0,3 \\
Indice de Iodo & $82,241^{\mathrm{a}} \pm$ & $83,360^{\mathrm{a}} \pm$ & $83,154^{\mathrm{a}} \pm$ & $80,705^{\mathrm{a}} \pm$ & $130-138$ \\
Índice de & 0,004 & 0,004 & 0,004 & 0,004 & \\
Refração & $1,458^{\mathrm{a}} \pm 0,001$ & $1,462^{\mathrm{a}} \pm 0,001$ & $1,468^{\mathrm{a}} \pm 0,001$ & $1,461^{\mathrm{a}} \pm 0,001$ & $1,473-1,477$ \\
Índice de & $186,878^{\mathrm{a}} \pm$ & $186,518^{\mathrm{a}} \pm$ & $188,989^{\mathrm{a}} \pm$ & $189,408^{\mathrm{a}} \pm$ & $188-194$ \\
Saponificação & 0,008 & 0,008 & 0,008 & 0,008 & \multirow{2}{*}{ Máximo 2,0 } \\
Matéria & $1,42^{\mathrm{a}} \pm 0,02$ & $1,45^{\mathrm{a}} \pm 0,03$ & $1,44^{\mathrm{a}} \pm 0,02$ & $1,47^{\mathrm{a}} \pm 0,03$ & Mán \\
Insaponificável & & & & & \\
\hline
\end{tabular}


Para o óleo extraído com o diclorometano, as análises de massa específica, índice de refração e índice de acidez, que revelam o nível de degradação do óleo, não se apresentaram dentro das normas especificadas pela ANVISA (1999) para óleo refinado. Outras análises, índice de saponificação, matéria insaponificável e índice de iodo se apresentaram dentro das especificações da agência citada, sendo esses resultados aplicados a ambas as variedades de sementes $\mathrm{e}$ às diferentes temperaturas de secagem.

Por outro lado, para o óleo extraído com o n-hexano como solvente, obteve-se que apenas as análises de índice de saponificação, apenas para a variedade Cabernet Sauvignon, e de matéria insaponificável ficaram dentro das especificações, devendo-se levar em consideração que o óleo analisado não foi submetido a nenhum tipo de tratamento após a extração.

As Tabelas 8 e 9 apresentam os valores de viscosidade, em cP, em temperaturas de 20 a $70{ }^{\circ} \mathrm{C}$ para o óleo de semente de uva.

Tabela 8 - Viscosidade do óleo de semente de uva extraído com diclorometano

\begin{tabular}{|c|c|c|c|c|}
\hline \multirow{2}{*}{$\begin{array}{c}\mathrm{T} \\
\left({ }^{\circ} \mathrm{C}\right)\end{array}$} & \multicolumn{2}{|c|}{$\begin{array}{l}\text { Cabernet } \\
\text { Sauvignon }\end{array}$} & \multicolumn{2}{|c|}{ Bordô } \\
\hline & $40^{\circ} \mathrm{C}$ & $80^{\circ} \mathrm{C}$ & $40^{\circ} \mathrm{C}$ & $80^{\circ} \mathrm{C}$ \\
\hline 20 & 33,70 & 42,90 & 17,50 & 26,00 \\
\hline 30 & 24,00 & 29,70 & 13,00 & 18,90 \\
\hline 40 & 17,60 & 21,30 & 10,30 & 14,20 \\
\hline 50 & 13,40 & 15,90 & 8,00 & 10,90 \\
\hline 60 & 10,30 & 12,00 & 6,30 & 8,60 \\
\hline 70 & 8,10 & 9,30 & 5,30 & 7,00 \\
\hline
\end{tabular}

Tabela 9 - Viscosidade do óleo de semente de uva extraído com n-hexano

\begin{tabular}{ccccc}
\hline \multirow{2}{*}{} & \multicolumn{2}{c}{ Cabernet } & \multicolumn{2}{c}{ Bordô } \\
$\left({ }^{\circ} \mathrm{C}\right)$ & \multicolumn{2}{c}{ Sauvignon } & \multicolumn{2}{c}{} \\
& $40^{\circ} \mathrm{C}$ & $80^{\circ} \mathrm{C}$ & $40^{\circ} \mathrm{C}$ & $80^{\circ} \mathrm{C}$ \\
\hline 20 & 40,42 & 27,11 & 63,03 & 44,64 \\
\hline
\end{tabular}

\begin{tabular}{ccccc}
\hline 30 & 27,18 & 20,50 & 43,12 & 30,35 \\
40 & 19,44 & 15,62 & 29,41 & 21,92 \\
50 & 14,06 & 12,11 & 20,62 & 16,40 \\
60 & 10,54 & 10,20 & 15,34 & 12,50 \\
70 & 7,81 & 8,35 & 11,93 & 9,96 \\
\hline
\end{tabular}

Por meio das Tabelas 8 e 9, observa-se que a viscosidade dos óleos analisados tem um comportamento decrescente em relação ao aumento da temperatura, comportamento esperado para todo líquido, e que, quanto maior a temperatura, menor esta variação.

Além disso, verifica-se que o óleo da variedade Cabernet Sauvignon extraído com diclorometano tem a viscosidade maior que a da variedade Bordô para o mesmo solvente, sendo que a $20{ }^{\circ} \mathrm{C}$, obtiveram-se valores de viscosidade de 33,70 e $42,90 \mathrm{cP}$ para a primeira variedade seca às temperaturas de 40 e $80{ }^{\circ} \mathrm{C}$, respectivamente, e, para a segunda, 17,50 e $26,00 \mathrm{cP}$ para a menor e maior temperaturas de secagem, respectivamente.

Em contrapartida, para o n-hexano, a viscosidade do óleo de semente de uva da variedade Bordô é maior que o da Cabernet Sauvignon, sendo que a $20{ }^{\circ} \mathrm{C}$, obtiveram-se valores de viscosidade de 63,03 e 44,64 cP para a primeira variedade seca às temperaturas de 40 e $80{ }^{\circ} \mathrm{C}$, respectivamente, e, para a segunda, 40,42 e $27,11 \mathrm{cP}$ para a menor e maior temperaturas de secagem, respectivamente.

Pode-se verificar, ainda, que no caso do diclorometano, enquanto a viscosidade do óleo aumenta quanto maior a temperatura de secagem das sementes, para ambas as variedades, para o n-hexano a viscosidade diminui aumentando a temperatura de secagem.

A Figura 7 mostra a relação da tensão de cisalhamento pela taxa de cisalhamento, à temperatura de $20^{\circ} \mathrm{C}$ para o óleo das sementes da variedade Cabernet Sauvignon secas à $40^{\circ} \mathrm{C}$ e extraído com diclorometano. 
Figura 7 - Tensão de cisalhamento por taxa de cisalhamento

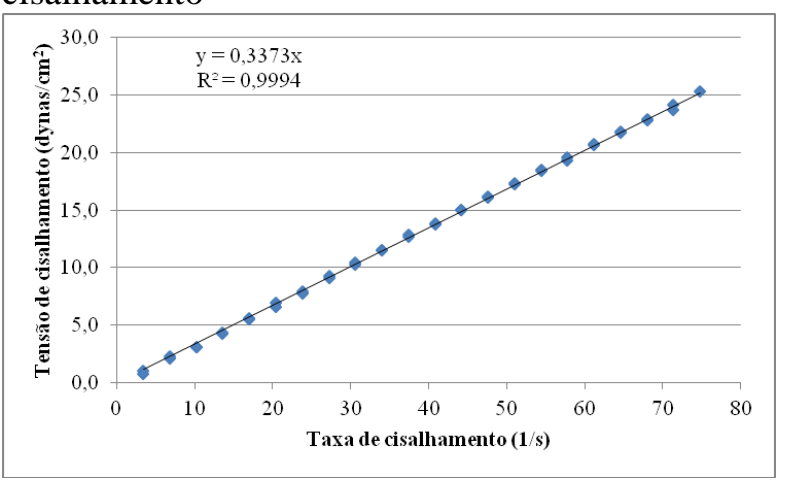

A Figura 7 mostra que a equação de reta tem bom ajuste para os dados experimentais, com o valor de $\mathrm{R}^{2}$ muito próximo de 1 , sendo que este mesmo comportamento também foi obtido para as demais condições. Além disso, a equação da reta ajustada tem coeficiente linear diferente de zero, o que classifica o óleo de semente de uva como fluido newtoniano.

\section{CONCLUSÃO}

Quanto ao processo de extração, foi verificado que os teores de óleo são maiores quanto maior a temperatura de secagem das sementes e maior o tempo de extração. Os maiores teores de óleo, $20 \%$ e $17 \%$, para as sementes de uva Cabernet Sauvignon e Bordô, respectivamente, foram obtidos utilizando sementes secas em elevadas temperaturas, $80^{\circ} \mathrm{C}$, tempo de extração de 16 horas e o diclorometano como solvente.

Quanto ao processo de caracterização, foi obtido que o óleo de semente de uva apresenta principalmente ácido linoleico em sua composição. Além disso, muitas propriedades físico-químicas avaliadas apresentam-se dentro das especificações da ANVISA (1999) para óleo de semente de uva refinado, mesmo que o óleo estudado não tenha passado por qualquer tratamento. Todos os óleos analisados apresentaram um comportamento de fluido que acompanha o modelo Newtoniano.
Assim, a produção do óleo de semente de uva a partir de uvas produzidas no país é uma alternativa promissora de utilização de um dos resíduos da vinificação, gerando um subproduto com alto valor agregado, tendo em vista a situação das empresas brasileiras que importam produtos a base deste óleo.

\section{NOMENCLATURA}

- \% Teor de óleo: é o teor de óleo extraído em cada experimento $(\mathrm{m} / \mathrm{m})$.

- $\mathrm{m}_{\text {óleo }}$ : é a massa de óleo extraída, em gramas.

- $\mathrm{m}_{\text {sementes}}$ : é a massa de sementes de uva utilizada na extração, em gramas.

\section{REFERÊNCIAS}

AHMADI, S. M.; SIAHSAR, B. A. Analogy of physicochemical attributes of two grape seeds cultivars. Food Technology, v.38, n.2, p.291-301, 2011.

ANVISA, 1999. Agência Nacional da Vigilância Sanitária. Disponível em: <http://www.anvisa.gov.br/legis/resol/48299.html>. Acesso em: 10/10/11.

BRASIL. União Brasileira De Vitivinicultura. Produção de uvas, elaboração de vinhos e derivados. Bento Gonçalves, Rio Grande do Sul, 2015. Disponível em: < http://www.uvibra.com.br/pdf/safra_uva20 03-2014.pdf $>$. Acesso em: 1 de junho de 2015.

CAMPOS, L. M. A. S. Obtenção de extratos de bagaço de uva Cabernet Sauvignon (Vitis vinifera): parâmetros do processo e modelagem matemática. 2005. Dissertação (Mestrado em Engenharia de Alimentos) - Universidade Federal de Santa Catarina, Florianópolis, 2005. 
CAO, X.; ITO, Y. Supercritical fluid extraction of grape seed oil and subsequent separation of free fatty acids by high-speed counter-current chromatography. Journal of Chromatography A, v. 1021, p. 117-124, 2003.

MORETTO, E.; FETT, R. Tecnologia de Óleos e Gorduras Vegetais na Indústria de Alimentos, Ed. Varela, São Paulo, 1998.

OLIVEIRA, D. A. Caracterização fitoquímica e biológica de extratos obtidos de bagaço de uva (Vítis Vinífera) das variedades Merlot e Syrah. 2010. Dissertação (Mestrado em Engenharia de Alimentos), Universidade Federal de Santa Catarina, 2010.

\section{AGRADECIMENTOS}

Agradecemos à Universidade Estadual de Maringá e ao CNPq pelos apoios estrutural e financeiro concedidos. 